\title{
EDUCAÇÃO, ÉTICA E CIDADANIA: REFERENCIAIS PARA AS ESCOLAS DA REDE SINODAL DE EDUCAÇÃO
}

\begin{abstract}
ALVORI AHLERT ${ }^{1}$
Resumo: Esta tese estudou as concepções de educação, ética e cidadania como referenciais para a Rede Sinodal de Educação. Parte-se da análise desses conceitos no contexto da Lei de Diretrizes e Bases da Educação Nacional, Lei Federal n. 9.394/96 que, apesar de representar a hegemonia do movimento neoliberal daquele período, possibilitou a construção de uma concepção emancipadora e libertadora de educação intercruzada com a ética e a cidadania. Para a Rede Sinodal de Educação, esta possibilidade passa pela compreensão de que a escola comunitária confessional luterana é uma escola pública não-estatal. E, ao assumir esta condição, ela pode reencontrar em Lutero e Comenius a concepção de uma educação emancipadora da pessoa humana fundada na ética e na cidadania; concepções e princípios que perpassaram os séculos e estiveram presentes na história das escolas comunitárias confessionais luteranas aqui erguidas pelos imigrantes alemães. Entretanto, o afastamento entre igreja e comunidades mantenedoras e as escolas comunitárias levou essas escolas a uma crise de identidade, de ética e de cidadania, sofrendo, assim, um processo de privatização empreendida pelas elites do seu entorno social. nas décadas de 1980 e 1990 . Neste sentido, a presente tese defende que o resgate da legitimidade das escolas comunitárias filiadas à Igreja Evangélica de Confissão Luterana no Brasil - IECLB passa pela ressignificação da concepção de educação emancipadora, adotando uma gestão administrativa e pedagógica democrática e participativa. Trata-se de uma ressignificação do ensino e da aprendizagem imbricada com o cotidiano da vida e uma avaliação humana que permite a autonomia do educando a partir dos princípios de uma política educacional da IECLB construída coletivamente, sustentada em princípios educacionais emancipadores e em princípios de uma concepção de ética e de cidadania gestados na história da cultura protestante com Martin Lutero e John Amos Comenius como expoentes da reforma luterana e da construção de um projeto pedagógico humanista, respectivamente, em consonância com os valores da pessoa humana, desenvolvidos desde o comunitarismo cristão; e hoje presentes e atualizados, de forma diferente, em pensadores humanistas como Paulo Freire e Jürgen Habermas.
\end{abstract}

Palavras-chave: Educação, ética, cidadania, História da Educação.

Abstract: This thesis studies the conceptions of education, ethics and citizenship as references for the Sinodal Net of Education. It starts from the analysis of these concepts into the context of the Lei de Diretrizes e Bases da Educação Nacional N. 9.344\96 that, instead of representing the hegemony of the neoliberal movement of that period, giving the possibility for the construction of an emanancipative and liberating of the intercrossing education with the ethics and the citizenship for the Sinodal Net Education, this possibility passes through the comprehensions that the Lutheran Confessional Community School is a non-stately public school. When assuming this condition, it can find again in Luther and Comenius the conceptions of an emancipative education of the human being based on ethics and citizenship, conceptions and

\footnotetext{
${ }^{1}$ Doutor em Teologia, Área Religião e Educação pelo IEPG/EST, RS, Mestre em Educação nas Ciências, pela UNIJUÍ, RS, Professor Adjunto da UNIOESTE, membro do GEPEFE - Grupo de Extensão e Pesquisa em Educação Física Escolar e do Grupo de Pesquisa Cultura, Fronteira e Desenvolvimento Regional. E-mail: alvoriahlert@hotmail.com, alahlert@brturbo.com.br, alvoriahlert@yahoo.com.br.
} 
principles that passed by the centuries and were present in the history of the Lutheran Confessional Community Schools built here by the German immigrants. Otherwise, the separation between the church community mantainantence and the community schools took these such schools to an identity, ethics and citizenship crises, suffering like this a privatization process in the decades of 80 and 90 attempted by the elites of its social environment. On this way, the present thesis defends that the rescue of the legitimacy of the community schools affiliated to IECLB passes by the ressignificance of the emancipative education conception, adopting an administrative and participative democratic pedagogical management a teaching and learning ressignificance connected to a life quotidian and to a human evaluation that forbids autonomy to the student, from the principles of an educational politics of the IECLB collectivity built, based on emancipative educational principles and on principles of an ethical and citizenship conception managed onto Protestant Culture History with Martin Luthero and John Amos Comenius as exponents of the Lutheran Reform and of a humanist pedagogical project construction respectively, according to the human being's values developed since the Christian communitarism, and today present and update in a different way, into humanist philosopher like Paulo Freire and Jürgen Habermas.

Keywords: Education, etchics, citizenship, Educational History.

\section{Introdução}

Este texto é uma síntese da pesquisa desenvolvida no Instituto Ecumênico de PósGraduação em Teologia, da Escola Superior de Teologia, em São Leopoldo, RS, para a obtenção do grau de Doutor em Teologia, entre os anos de 2001 a 2004. (AHLERT, 2004) Desenvolvemos uma tese para mostrar que, no século XX, as décadas de 80 e 90 foram de muitas e profundas transformações no mundo e em nosso país. Por um lado, a abertura política forjada e construída pela participação de sindicatos e igrejas significou um retorno da possibilidade do exercício da democracia. Nesta conjuntura, a sociedade civil organizada, juntamente com os representantes do povo nos parlamentos, possibilitaram a construção de uma Constituição que acolheu muitos dos anseios e clamores da população. Entretanto, o revés imposto pelo movimento neoliberal inibiu o efetivo avanço de políticas públicas democráticas. Na área da educação, a Nova LDB -Lei N. 9.394/96 refreou os impulsos de grandes mudanças, mas mesmo assim permitiu a inclusão de algumas questões importantes para um projeto educacional emancipador e libertador ao comprometer a educação com a formação de um sujeito ético e cidadão através da inclusão de temas transversais como a ética e a cidadania e de bases e exigências de uma gestão democrática, 
além da construção de projetos políticos pedagógicos participativos via comunidades escolares.

Por outro lado, o revés imposto pelo movimento neoliberal significou também o controle político das elites globalizadas sobre a educação, transformando-a na grande solução para todos os problemas, desde que fosse, não mais um direito, mas um serviço, um produto a ser comercializado segundo os padrões de qualidade total estabelecidos pelas políticas empresariais do capitalismo voraz do movimento neoliberal. Assim, cooptaram os conceitos de educação, ética e cidadania como elementos privativos do ideário neoliberal.

Por isso nossa investigação buscou reencontrar as discussões sobre um conceito de educação que significa a emancipação e a libertação do ser humano a partir de sua realidade e de sua cultura. Dessa forma, fundamentados em teóricos do projeto humanista, desenvolvemos a idéia da inseparabilidade entre educação, ética e cidadania. Cada uma pertença à outra, pois são três dimensões da humanização do ser humano que são interdependentes na busca da emancipação e da libertação. Portanto, trata-se de uma ética do ser humano, que busca a defesa da vida e da construção de ações e políticas que se contraponham à objetificação ou coisificação do ser humano e a mercantilização da vida levado a cabo pela privatização dos corações, das mentes e das almas de quem está envolvido no processo educativo. Por isso, uma educação que transforme seu caráter para possibilitar a construção da humanização do ser humano deve ser instrumento de aprendizagens coletivas; promover a discussão pública, aberta e participativa de todos os seres humanos; construir conhecimentos que superem o individualismo e o egoísmo liberal e estimulem a cooperação e a solidariedade.

Somente esta educação ética pode gestar o verdadeiro cidadão. Não num processo primeiramente teórico para que esse sujeito venha a exercer a cidadania posteriormente, mas uma cidadania que se construa no próprio processo ético-educativo, conduzido através de ações democráticas e participativas de todos os envolvidos na formação escolar e não-escolar. Uma cidadania que não se realiza por meio de decretos, mas que significa participação ativa capaz de conduzir a educação para o confronto com as reais condições sociais, políticas e econômicas que demandam justiça e eqüidade política, social e econômica. Uma cidadania que supere a democracia representativa e desenvolva uma democracia direta para um efetivo controle do Estado por parte da população e que, assim, possibilite a construção de políticas públicas humanizadas e inclusivas. Essa educação para a cidadania é, pois, pressuposto para a vivência da 
democracia. Uma educação que se constitui num ato ético e político através da cidadania ativa, onde todos são responsáveis por todos.

\section{Distinções entre educação privada e educação comunitária}

A partir desses elementos, discutimos a relação entre ensino privado e ensino comunitário. Considerando que a Nova LDB-N.9.394/96 define as categorias de instituições de direito privado em particulares em sentido estrito, comunitárias, confessionais e filantrópicas, buscamos a distinção entre o comunitário e o privado com vistas ao nosso projeto relacionado com as escolas da Rede Sinodal de Educação. Do ponto de vista legal, ético e histórico definimos a escola evangélica luterana como uma escola confessional comunitária. Isto significa que ela é uma escola pública não-estatal. Sua origem comunitária foi atestada pelos seus elementos históricos constitutivos arrolados e descritos no capítulo dois.

A história da educação no Brasil tem na educação confessional comunitária sua base fundacional. Ainda que tenha sido uma transposição da cultura, a educação jesuítica embrionou a educação comunitária no Brasil. Com o processo imigratório, as outras confessionalidades também desenvolveram uma significativa rede de educação comunitária. Esta educação comunitária tem passado por longas polêmicas, por que, por uma falta de clareza definitória, muitas vezes tem sido confundida com educação privada. Ela própria muitas vezes tem assumido a condição de instituição privada descaracterizando sua identidade e seu condicionamento histórico.

Neste contexto, as experiências do ensino superior têm dado a melhor contribuição de conhecimentos e discussões acumuladas sobre a distinção entre o privado e o comunitário em educação. Suas demandas e necessidades obrigaram a definição de sua atuação no campo legal no contexto da referida LDB. São experiências que nasceram de comunidades locais e regionais e permitiram o controle social destas comunidades sobre estas instituições. Suas condições de instituições públicas não-estatais devem ser exemplo para a concepção de educação, de gestão democrática e de construção participativa do projeto político educacional para as escolas comunitárias filiadas à Rede Sinodal de educação.

Com o entendimento de que as escolas evangélicas de confissão luterana são efetivamente escolas comunitárias, portanto, públicas não-estatais, acreditamos que se abre para elas um importante horizonte para justificar e definir sua existência nos sistemas estaduais e federais de 
educação. Justificativas de definições que obrigam a uma gestão democrática e participativa dos recursos para sua aplicação ética e socialmente cidadã e a construção de seu projeto político pedagógico amplamente consensuado pela comunidade escolar, comunidade mantenedora e entorno social.

\section{Concepção protestante de educação, ética e cidadania}

Esta perspectiva nos levou a uma leitura interpretativa das concepções protestantes sobre educação, ética e cidadania em Lutero e Comenius. Para Lutero a educação é instrumento fundamental para o exercício da vida cristã. Assim, a Reforma tornou-se a primeira escola do povo alemão, impulsionando a educação pública. Lutero desafiou a sociedade de então para a responsabilidade com a educação e a formação da juventude. Não se trata de uma educação apenas direcionada para a formação de quadros para a igreja, mas de uma educação que objetivava a formação integral do ser humano. Educação integral, de perspectiva construtivista e lúdica, que preparasse a pessoa para o conhecimento de Deus, o conhecimento do mundo no sentido de viver este mundo segundo os critérios cristãos, de justiça, honestidade e responsabilidade pública. Uma educação que premonizou a concepção freireana que vê na educação um processo de humanização do ser humano; uma forma de tornar o ser humano mais ser humano. Segundo Lutero, esta educação deveria ser assumida pelo Estado, em parceria com a família e a comunidade confessional. Esta defesa permitiu afirmar que no contexto luterano as proposições de Lutero deram início à escola público-comunitária sustentada pelo Estado e por quem pode contribuir financeiramente com ela.

Lutero desenvolveu o embrião para uma compreensão sobre a importância e as possibilidades do poder local. Um poder que está próximo da população. Esta perspectiva se construiu, sobretudo, na luta contra a pobreza e a mendicância, por meio de uma assistência social organizada de forma democrática. "Lutero é um dos principais líderes religiosos a fundamentar uma ética democrática.” (PAULY, 2002, p.149)

A organização da assistência social decorre da reforma do culto que Lutero promoveu. Sua teologia reivindica a superação do dualismo que permitia uma separação entre a vida espiritual e as ações concretas do cotidiano. Sua hermenêutica bíblica permitiu-lhe restaurar o sentido do culto cristão. Este deve traduzir-se para dentro da vida, do cotidiano das pessoas. Por isso, o sacramento da Ceia do Senhor deve provocar uma nova ética social, 
pois, como sinal de uma comunhão radical em Cristo, compromete o ser humano a viver concretamente esta comunhão com a comunidade e com a cidade. A comunidade e a cidade tornam-se um só corpo e seus cidadãos pertencem uns aos outros.

A analogia feita por Lutero entre a relação mútua de sacramento e ética social e os benefícios e responsabilidades da cidadania é notável no que diz respeito à relação entre a Reforma e as cidades. O uso correto do sacramento edifica a comunidade. Desta forma, a pessoa em necessidade recebe a recomendação de que dirija-se alegremente ao Sacramento do Altar e deponha seu pesar na comunidade, busque ajuda junto a todo o corpo espiritual, assim como um cidadão pediria auxílio às autoridades e concidadãos. (LINDBERG, 2001, p.142)

Essa ética social constitui-se em uma experiência político-econônica democrática e cidadã introduzida inicialmente em duas cidades. A primeira foi em Wittenberg. Em janeiro de 1522 esta cidade aprovou sua Constituição através de um conselho da cidade. Nela Lutero e Karlstadt fizeram contribuições substanciais. Conforme Lindberg, dos 17 artigos, 14 legislavam em favor de auxiliar os pobres e enfrentar a pobreza. Foi instituída uma caixa comum para servir de custeio aos necessitados, e possibilitar captação de recursos para emprestar a juros baixos para trabalhadores e pequenos artesões com o objetivo de melhorar sua situação de vida e possibilitar melhorias no trabalho e na produção. Mas, para o nosso interesse, a principal contribuição da caixa municipal era o financiamento da educação para as crianças pobres. A captação dos recursos se dava por meio de orçamentos das instituições religiosas e de propriedades pertencentes a igrejas, que foram desfeitas pelo conflito. Quando os recursos não supriam as necessidades, um artigo constitucional previa a arrecadação de impostos entre as diferentes camadas da população.

Muitas das caixas - e ordens esmoleiras, foram publicadas por meio de impressos. Especialmente visíveis e exemplares foram as que Karlstadt influenciou através da Ordem louvável do principado de Wittenberg, de 1522, que foi precedida desde 1521 por variadas ordens mendicantes pela inspiração de Lutero, assim como a do prefácio dele que guarnece a caixa comum de Leisnig, de 1523. (LAUBE, 1983, p.148-19) 
A Constituição de Leisnig, elaborada pelo Conselho da cidade, recebeu importante contribuição de Lutero. Nela são definidos os estatutos para a administração da caixa comum, sobre as orientações de como lidar com as propriedades comuns da igreja, sobre o direito e a autoridade das assembléias comunitárias e sobre a nova ordem do culto nas comunidades. Os objetivos da caixa comum não se restringiram a um assistencialismo para com a população pobre, conforme já apresentado acima. Tratava-se de um programa mais global para superar a pobreza.

Em termos de assistência direta aos pobres, a constituição regulamentou desembolsos em empréstimos e doações para recémchegados a fim de auxiliá-los a se estabelecer na cidade: para os pobres com casa que, depauperados por circunstâncias fora de seu controle, moravam em sua própria residência e não pediam esmolas em público, a fim de ajudá-los a se firmar num negócio ou numa ocupação; e para os órfãos, dependentes menores, inválidos e idosos, a fim de prover seu sustento diário. (LINDBERG, 2001, p.148)

Não há dúvida que por detrás dessa organização estava uma dimensão política de cidadania democrática bem significativa e, de certa forma, deslocada no seu tempo. Tal democracia participativa estava adiantada em vários séculos. Em meio ao regime feudal, as cidades inspiradas nestes princípios buscavam, por meio da participação popular, a sua organização política, econômica e social. No Acordo fraternal da caixa comunitária de toda a comunidade de Leisnig (1523), no título que trata sobre bens, reservas e receitas da caixa comunitária, transparece claramente que as decisões acerca do assunto foram construídas coletivamente através de assembléias comunitárias. Vale a pena reproduzir o referido acordo.

A fim de que nossa fé cristã, na qual todo temporal e eterno foi obtido e a nós comunicado por pura graça e misericórdia pelo Deus eterno através de nosso senhor e redentor Cristo, venha a produzir e seja levada a produzir o fruto verdadeiro do amor fraternal e este amor se concretize na verdade e nas obras de bondade e humildade, nós, a assembléia geral antes mencionada, ordenamos, instalamos e estabelecemos unanimemente para nós e nossos descendentes uma caixa comum. Por este documento e por força deste nosso acordo fraternal, ordenamos, instalamos e estabelecemos a mesma para o propósito e da maneira e forma a seguir arrolados. 


\section{Atribuições e recursos da caixa comum:}

Portanto, nós, a assembléia paroquial e nossos descendentes, doravante queremos alimentar, prover e manter com recursos de nossa caixa comum e através de nossos dez administradores eleitos, na medida de nossos bens e com a graça de Deus, os seguintes títulos de despesas, conforme o respectivo caso, ou seja: despesas com o ministério pastoral; despesas com a sacristia; despesas com a escola; despesas com os inválidos e idosos pobres; despesas com o cuidado das crianças órfãs e pobres; despesas com o cuidado de pessoas sem casa; despesas com o cuidado de migrantes; despesas com manutenção e construção de prédios; despesas com a compra de cereais para estoque [regulador] comum; acrescentar à caixa comum qualquer receita [auferida]. (ALTMANN, 1994, p.213-214)

A pesquisa de Carter Lindberg (2001, p.146-147) atesta a organização democrática e participativa da constituição da caixa comunitária. A administração se efetivava através de representantes eleitos pela comunidade. Tratava-se de dez administradores: dois membros indicados pela nobreza, dois membros do Conselho da cidade, três cidadãos comuns da cidade e três representantes dos camponeses. Toda a movimentação financeira devia ser registrada em livros guardados em caixa-forte da igreja, trancados com diferentes chaves segundo os grupos envolvidos no processo. Relatórios trienais deviam ser apresentados à comunidade pelos seus diretores.

Concluímos que a grande tarefa dessa escola é a formação de pessoas éticas e cidadãs. Pessoas capazes de organizar o convívio social, político e econômico segundo critérios bíblicos de justiça, honestidade e retidão, para que cada comunidade e cidade se organizem de tal forma para que todos tenham acesso à educação, a um trabalho que permita o acesso ao pão de cada dia. E que aqueles que não puderem realizá-lo por alguma deficiência sejam carregados pela comunidade diaconal. Tudo isso a partir da caixa comunitária, administrada democraticamente por um conselho representativo de todos os segmentos sociais, conforme a Constituição de Leisnig.

Na esteira destas proposições, Comenius aprofundou estes ideais da educação. Este teólogo e pedagogo, aproximando Teologia com Pedagogia, radicalizou a democratização da educação, exigindo igualdade de acesso para homens, mulheres, ricos e pobres, indistintamente. "Jogou todas as fichas” na educação. Uma educação grávida de um humanismo profundo, fundamentada na pessoa de Jesus Cristo. Uma educação que respeita e valoriza o professor e que tem como 
função especial a humanização do ser humano. Esta perspectiva também levou-o a desenvolver seu conceito de educação que deve formar para a autonomia, para que o ser humano não seja apenas um espectador do mundo, mas um ator que participa de sua transformação.

Por isso sua concepção de educação estava imbricada com as dimensões da ética e da cidadania. Do ponto de vista da ética, defendeu uma educação que ensinasse as virtudes, a retidão, a honestidade, a prudência, a fortaleza e a justiça. Virtudes a serem aprendidas não através de palavras, mas através de ações concretas no contexto escolar e social.

Em suma, tanto em Lutero quanto em Comenius, a historiografia educacional, que no nosso entender ainda não reconheceu devidamente estes pensadores, tem uma referência importante para a concepção humanista de educação e sua inseparabilidade com a ética e a cidadania. Com suas críticas e propostas educacionais, ambos os pensadores humanistas vislumbraram e projetaram a ética e a cidadania como lugares privilegiados da educação.

Estas bases históricas e filosóficas acima apresentadas nos deram a lente para a leitura interpretativa da história da rede de escolas evangélicas no Brasil e de suas concepções educacionais pensadas, construídas e refletidas no período mais recente compreendendo as últimas duas décadas do séc. XX, segundo os documentos oficiais das agremiações que representam a direção da Igreja Evangélica de Confissão Luterana no Brasil - IECLB e de sua rede de escolas hoje reunidas na Rede Sinodal de Educação.

\section{A constituição da escola comunitária evangélica de confissão luterana e sua concepção de educação, ética e cidadania nas décadas de 80 e 90}

A história dessas escolas comunitárias confunde-se com a própria história da IECLB. Como igreja de imigração, seus precursores formaram comunidades religiosas e sociológicas sustentadas na fé luterana e na educação comunitária. Os exemplos históricos acima apresentados mostram que as escolas evangélicas têm sua origem no esforço comunitário, tanto na sua construção quanto na manutenção. Esta rede de escolas, de significativo número nas primeiras décadas da imigração, recebeu importante impulso na era do pastor Hermann Gottlieb Dohms, cujo o projeto eclesiástico demandou forte investimento numa estrutura escolar. Isso significou que naquele período, primeira década do século passado, as escolas evangélicas possuíam um objetivo bem definido e, portanto, uma identidade com a função de preparar as lideranças 
comunitárias. Tinham um programa de formação de pastores e professores provenientes do grupo étnico teuto-brasileiro, para fomentar a constituição de comunidades confessionais luteranas de bases populares e independentes em solo brasileiro.

Na maioria dos países da América Latina as primeiras escolas foram construídas pelas igrejas. São as escolas confessionais ou comunitárias. No catolicismo destacaram-se as escolas ligadas a ordens religiosas, como os jesuítas, os maristas, os camilianos, os salesianos, etc. Também as igrejas protestantes trouxeram a educação como um dos pilares fundamentais de sua missão.

Muitas comunidades evangélicas conjugavam com naturalidade, no mesmo ambiente, a atividade escolar e a celebração de ofícios religiosos. As escolas confessionais, também chamadas de comunitárias, exercem até hoje um papel importante na tarefa educativa dos cidadãos. (STRECK \& WACHS, 1998, p. 255)

Com o processo imigratório da Europa no século XIX, experimentou-se um vistoso florescimento de escolas elementares comunitárias no Brasil. Lúcio Kreutz afirma que, “[...] o número mais expressivo de escolas étnicas foi dos imigrantes alemães, com 1.579 escolas, em 1937, seguindo-se os italianos, com 396 escolas em 1913 (e 167 na década de trinta). Os imigrantes poloneses tiveram 349 escolas e os japoneses 178 (ou 260, ou 486?), também na década de trinta” (KREUTZ, 2000, p. 161). Assim como o missionarismo católico apostólico romano, também o protestantismo trouxe importante contribuição para a educação brasileira a partir do século XIX.

No caso da Igreja Evangélica de Confissão Luterana no Brasil - IECLB, havia, no início da década de 70, cerca de cem escolas de ensino primário ou fundamental e trinta escolas de ensino médio, entre elas algumas escolas com cursos técnicos. Neste período, o conjunto de educandários ligados a IECLB contava com cerca de vinte mil alunos matriculados. O trabalho era coordenado pelo Departamento de Educação e de Catequese da IECLB (cf. KELLER, 1970, p. 56). Conforme Danilo R. Streck, "Para suprir a lacuna da falta de escolas públicas chegou a haver, nos sínodos, mais de 400 escolas confessionais luteranas, contra as pouco mais de 100 que existem (ou resistem) atualmente”. (STRECK, 1995, p. 31) 
Já nas décadas de 50 e 60, as escolas enfrentaram duras crises decorrentes da nacionalização imposta pelo Estado Novo. O reerguimento das escolas comunitárias evangélicas, mais uma vez, teve nas comunidades evangélicas seu mais forte sustento.

No início da década de 80 foram instituídos o Conselho de Educação da IECLB e a Associação Evangélica de Educação afetos ao Departamento de Educação da IECLB. Conforme seu regimento, o Departamento de Educação tem o objetivo de coordenar as ações da IECLB no campo da educação formal, portanto, gerir sua política educacional. A Associação Evangélica de educação e ao Conselho de Educação cabem a análise da realidade escolar, o lançamento das bases do Departamento de Educação, o apoio à rede de escolas no seu posicionamento e inserção na realidade educacional do país; o acompanhamento das ações da Secretaria Executiva, entre outros.

Mas, as transformações ocorridas dentro da IECLB ao longo das duas décadas em questão também provocaram a reestruturação e adequações nas escolas evangélicas, originando a Rede Sinodal de Educação, atualmente constituída de 53 escolas com cerca de 35.000 matrículas na Educação Infantil, Educação Básica e Ensino Superior.

\section{A constituição da Rede Sinodal de Educação}

Até 1980, a relação orgânica estrutural, para além da relação direta que sempre houve entre comunidade confessional local e escola comunitária, se estabelecia através do Departamento de Educação e do Centro de Diretores de Escolas Evangélicas (CDEE). Em 24 de fevereiro de 1981, nas dependências da Sede da IECLB, em Porto Alegre/RS, foi instituído o primeiro Conselho de Educação da IECLB. O ato de instalação aconteceu com um culto celebrado pelo Presidente da IECLB, P. Augusto Ernesto Kunnert. (Cf. IECLB Departamento de Educação. Livro de Atas do Conselho de Educação (1981-1985), folha 2) Neste mesmo dia, o Centro de Diretores de Escolas Evangélicas (CDEE) transformou-se na Associação Evangélica de Educação. “Aos 24 dias de fevereiro de 1981 reuniu-se em sua Primeira Assembléia Geral Ordinária a Associação Evangélica de Educação, em Porto Alegre, em dependências da Igreja Evangélica de Confissão Luterana no Brasil, com a presença dos representantes supra - assinados.” (IECLB - Departamento de Educação. Livro de Atas da Associação Evangélica de Educação (AEE): 1981-1990, folha 2 verso). 
A partir de então, o Departamento de Educação passou a ser constituído pelos seguintes órgãos: a) Associação Evangélica de Educação; b)Conselho de Educação IECLB. c) Direção Executiva. O citado Regulamento do Departamento de Educação especifica, assim, seus objetivos no artigo $6^{0}$ :

a) coordenar os esforços da Igreja Evangélica de Confissão Luterana no Brasil - IECLB no campo educacional escolar;

b) exercer a orientação geral dos estabelecimentos de ensino evangélicos no desempenho de sua tarefa, visando uma unidade de propósitos em função do vínculo que os caracteriza, respeitada a autodeterminação de cada entidade mantenedora;

c) estimular o intercâmbio e o congraçamento de todos os estabelecimentos escolares no âmbito da Igreja Evangélica de Confissão Luterana no Brasil - IECLB;

d) participar, através de suas estruturas de representação, da condução dos processos da educação no país, mediante colaboração em todos os órgãos educacionais - oficiais ou não - a que tiver acesso;

e) promover o aperfeiçoamento do ensino em geral e do ensino religioso, em particular, bem como dos setores administrativos das escolas evangélicas;

f) cultivar o intercâmbio com entidades congêneres;

g) promover congressos, seminários, cursos de aperfeiçoamento, encontros de estudos - nacionais ou regionais - de acordo com as necessidades;

h) editar, divulgar ou intermediar periódicos, trabalhos e publicações que visem ao aprimoramento no trabalho das escolas;

i) expedir recomendações de ordem geral, inclusive sobre remuneração do pessoal docente e administrativo;

j) prestar assistência técnica aos estabelecimentos, assessorando-os conforme a necessidade. (Departamento de Educação IECLB. Regulamento).

O mesmo regulamento também define as competências da Associação Evangélica de Educação (AEE), hoje denominada de Rede Sinodal de Educação, e do Conselho de Educação, respectivamente:

a) analisar a realidade escolar, debater alternativas e levantar sugestões de atividades;

b) informar-se de todos os assuntos que sejam do interesse das Escolas; 
c) lançar as bases de trabalho do Departamento de Educação para o período seguinte;

d) apreciar o Relatório de Atividades do Diretor-Executivo;

e) tomar conhecimento do Relatório do Presidente do Conselho de Educação;

f) nomear Conselheiros do Conselho de Educação;

g) resolver sobre as contribuições financeiras para a manutenção do Departamento de Educação;

h) resolver ou encaminhar para solução todos os assuntos que lhe forem submetidos à apreciação;

i) decidir sobre a admissão de novos associados;

j) decidir sobre a alteração do presente Regulamento.”(Art. 13).

“a) analisar questões da educação, procurando interpretar e posicionar-se diante da realidade educacional brasileira;

b) interpretar o pensamento da Associação Evangélica de Educação, na forma dos registros de decisões tomadas pelas Assembléias Gerais, traduzindo-o em diretrizes para a ação concreta da DireçãoExecutiva;

c) emitir pareceres ou orientação sobre assuntos específicos, submetidos a sua apreciação;

d) emitir normas para o funcionamento da Direção-Executiva, quando necessário;

e) fixar a remuneração de pessoal ligado à Direção Executiva;

f) indicar ao Conselho Diretor da Igreja Evangélica de Confissão Luterana no Brasil - IECLB, ouvida a Assembléia Geral da Associação Evangélica de Educação, para aprovação, o DiretorExecutivo a ser nomeado pela Diretoria da Instituição Sinodal de Assistência, Educação e Cultura - ISAEC;

g) pronunciar-se sobre qualquer assunto que lhe seja submetido pela Direção-Executiva;

h) elaborar seu Regimento. (Art. 21).

Assim, o Departamento de Educação é o órgão da IECLB que coordena as atividades relativas ao setor da educação formal, ou seja, as escolas que possuem vínculos com comunidades ou paróquias e as entidades mantenedoras das escolas que possuem algum vínculo com a IECLB.

A Rede Sinodal de Educação, constituída pelas escolas filiadas, busca hoje uma expansão em duas frentes. Num crescimento horizontal, quer alcançar as áreas de colonização mais recentes, como, por exemplo, o Instituto Luterano de Educação de Parecis, Campo Novo do Parecis/MT, fundado em 1996. Numa tentativa de verticalização, foram criados cursos de nível superior e de pós-graduação lato sensu, em Curitiba/PR, Joinville/SC, Ivoti/RS, Três de Maio/RS, Horizontina/RS, além da Escola Superior de 
Teologia que já possuía curso de pós-graduação stricto sensu (mestrado e doutorado) com nível de excelência segundo a avaliação do MEC. ${ }^{2}$

O Ingresso de instituições da rede de escolas no ensino superior foi um processo lento e tímido até o momento. Ao final da década de 60 o Conselho de Educação entendia que a igreja deveria relacionar-se com o ensino superior através de um outro tipo de ações, como acompanhamento dos estudantes e docentes envolvidos nas universidades, além de contribuir com infra-estrutura para estudantes poderem se manter na universidade com a mobilização dos luteranos em favor de bolsas de estudo para jovens se manterem na universidade. Somente 20 anos depois é que o Conselho de Educação emitiu seu primeiro parecer favorável para o ingresso da IECLB no ensino superior.

É dessa realidade, estrutura e vínculos entre IECLB e escolas que emanaram os elementos de uma concepção educacional da IECLB. E um dos elementos que contribuiu para o conceito de educação da rede de escolas foi o posicionamento ético, social e político da IECLB através do Manifesto de Curitiba, que significou uma posição corajosa frente a uma realidade de opressão, tortura, mordaça, terror e medo. Este documento fez a defesa de uma educação democrática e integral para o ser humano.

Tal posicionamento veio na seqüência de um manifesto dos docentes da Faculdade de Teologia, que em 1978 também haviam se pronunciado em favor de uma educação libertadora, que promovesse aprendizagens colocadas na inter-relação entre o estudo teórico e a prática eclesial dentro da realidade brasileira.

Esta consciência libertadora do final da década de 70 e início dos anos 80 exerceu uma pressão bastante forte sobre as escolas. Uma das primeiras ações da Secretaria Executiva da Rede e do Conselho de Educação foi a realização de uma pesquisa sobre a visão que os Obreiros e comunidades da IECLB tinham das escolas evangélicas. E os resultados foram a esposição de críticas contundentes contra a elitização da escola evangélica. Isto provocou uma reação do Conselho de Educação no sentido de buscar uma concepção de educação para a sua rede de escolas. E as primeiras posições sobre essa concepção foram firmadas pelo Conselho de Educação que propôs uma educação que proporcionasse o desenvolvimento das potencialidades dos alunos; o desenvolvimento da capacidade de pensar; a busca da verdade e do caráter; que

2 Cf. Fundação Coordenação de Aperfeiçoamento de Pessoal de Nível Superior Avaliação da PósGraduação. SÍNTESE DA AVALIAÇÃO. Período Avaliação: 1998/2000 - Avaliação. EST - RS TEOLOGIA M/D. Cons. 7. 24/08/01 às 18:50 1 de 1. 
provocasse transformações do ser humano e da sociedade; que ligasse o conhecimento como a verdade e a afetividade. Esta concepção deveria impulsionar a sociedade para um processo emancipador e libertador. Para isso a educação deveria ser planejada a partir da realidade, o que pressupõe o envolvimento da comunidade escolar e eclesial e um currículo construído a partir da realidade.

Estas concepções foram ratificadas e aprofundadas através de palestras que permitiram vincular estas concepções ao resgate dos princípios luteranos de educação para que a educação pudesse atingir especialmente os mais necessitados e marginalizados. Uma educação integral, formadora da pessoa toda, em todas as esferas de sua existência, que promovesse o desenvolvimento comunitário e que contribuísse para o desenvolvimento de um pensamento crítico e autônomo contra uma realidade ideologizada e escravizante.

Estas posições levaram a uma proposição de uma educação popular, construída de baixo para cima, isto é, a partir da base, para que o saber do povo pudesse expressar e articular seus anseios por emancipação e libertação. Estas posições foram desenvolvidas ao longo do ano de 1985, com o Tema da IECLB: “Educação: compromisso com a verdade e a vida."

O referido Tema do Ano permitiu o debate dos grandes temas nacionais da educação, como o acesso à educação e o compromisso com uma educação libertadora por meio de uma práxis dialética, portanto processual. Esta concepção ainda significou uma aproximação da concepção luterana de educação com a pedagogia freireana de educação libertadora.

Havia, até este momento, uma relativa congruência entre as lideranças e obreiros eclesiásticos da IECLB e o Conselho de Educação no tocante aos conceitos e tarefas da educação evangélica de confissão luterana. Neste período o Conselho chegou a emitir um posicionamento favorável a educação popular. Propôs uma educação para a formação de um ser humano crítico, solidário e livre, capaz de exercer a denúncia da injustiça, o anúncio da Boa Nova do Evangelho e serviço ao próximo, ao outro.

Estas concepções e conceitos também apontaram para um conceito de escola evangélica. Entretanto, começou a perceber-se uma perda do vínculo entre as comunidades mantenedoras e suas escolas, creditada na época à quebra da homogeneidade social, econômica e cultural sentida com intensidade em meados da década de 80. Reclamou-se uma definição mais clara para os objetivos da escola evangélica e sobre os grupos com os quais ela deveria atuar prioritariamente. 
Na mesma direção se posicionaram os Concílios Gerais, órgãos máximos decisórios da IECLB constituídos por representantes das paróquias e comunidades, defendendo uma educação de base popular que visasse a realidade brasileira e a formação de um ser humano participativo, ético, honesto e lutador contra a corrupção.

Todas estas ações levaram a um posicionamento do Conselho de Educação com vistas ao processo da Constituinte brasileira em construção na segunda metade da década de 80 quanto à área da educação. Por meio de um documento emanado do XVI Congresso Nacional de Professores Evangélicos, reafirmaram-se os objetivos e diretrizes para a formação de um ser humano íntegro, crítico, participativo e solidário, bem como a reivindicação do reconhecimento da escola comunitária no sistema educacional do país.

Outra contribuição importante desse documento é a afirmação da necessidade em resgatar a comunidade como o lugar e a expressão da verdadeira e autêntica ação pública, devolvendo ao cidadão sua condição de partícipe da construção de uma sociedade democrática. Neste período o Conselho de Educação também emitiu parecer sobre princípios para o ensino superior. Estes princípios afirmam que o ensino superior deveria primar pela visão antropológica que caracteriza os princípios pregados pela IECLB, segundo o Evangelho de Jesus Cristo e a identidade luterana. Ainda propôs a gestão democrática da administração, com base em estruturas de Fundação Comunitária.

No início da década de 90 o Conselho Diretor da IECLB, juntamente com um representante do Conselho de Educação, aprovou as diretrizes de uma política educacional da IECLB. Este documento justificou teológico e biblicamente a responsabilidade da igreja para com a educação. Propôs uma educação transformadora da realidade socialmente injusta, através da integração da escola, família e igreja; o desenvolvimento da formação integral do ser humano; o fortalecimento dos laços de solidariedade; do favorecimento da liberdade, da honestidade e de compromissos responsáveis com uma vida familiar, profissional, social e comunitária; e uma educação como condição permanente e sempre inacabada.

Entretanto, os limites dessas diretrizes estão no próprio processo de construção, no qual toda a riqueza de participação comunitária experienciada pelos debates do Tema da IECLB sobre educação não foram aprofundadas, porque as diretrizes saíram de um grupo de "notáveis", ou seja, de um processo democrático apenas representativo tornando-se, assim, um documento de consumo sem explicitar a quem se dirige. E o principal sintoma desse processo veio logo em 
seguida com a decisão do Conselho Diretor da IECLB em desligar o vínculo deste com a rede de escolas, dando autonomia absoluta à rede de escolas. A partir daí enfraqueceram-se cada vez mais os elos entre a igreja e suas comunidades com a rede de escolas evangélicas.

Este distanciamento provocou uma perda da identidade luterana da rede de escolas, jogando a rede para uma prática individualista e para uma centralização do poder segundo critérios políticos do movimento neoliberal, a ponto de o Conselho de Educação chegar a publicar em 1994, uma cartilha de qualidade total para as suas escolas, totalmente descaracterizada de sua concepção luterana de educação ética e cidadã. Este manual assumiu critérios pedagógicos duvidosos, como por exemplo, na área da avaliação.

Este vácuo de rumos e planejamentos, com uma identidade luterana clara e bem definida, levou no final dos anos 90 a uma Pré-Consulta sobre Educação Formal patrocinada pela IECLB e pelo Conselho de Educação. Este evento veio ratificar com clareza que a rede de escolas perdera sua identidade luterana, seus princípios educacionais historicamente construídos desde a Reforma Luterana. As proposições assumidas nesta Pré-Consulta já não conseguiram alcançar a clareza e o vigor dos posicionamentos políticos, sociais e econômicos anteriores, uma característica da postura luterana. Da mesma forma não conseguiram se aproximar de uma concepção mais clara de educação outrora construída e divulgada. Perdeu-se a convicção emancipadora e libertadora da educação.

Da mesma forma o documento reafirmou, acomodou e aceitou o distanciamento entre a escola comunitária e sua comunidade mantenedora como um fato natural. Isso significou a reafirmação da política implementada no início da década de 90 quando se firmou a independência da rede de escolas em pleno auge de vivências do movimento neoliberal, ideário que entrou no país com força naquele período, o que levou a uma centralização do poder na rede de escolas e um rompimento pernicioso do controle comunitário sobre a escola comunitária pública não-estatal.

Ainda defendemos a tese de que, a partir dos embates das políticas públicas de educação nas décadas de 80 e 90, são reais as necessidades de uma educação emancipadora e libertadora fundada em valores éticos e cidadãos, o que, por força das organizações populares, foi incluído nos compromissos e desafios estabelecidos na Nova LDB N. 9.394, de 20 de Dezembro de 1996; que as escolas da Rede Sinodal de Educação são escolas efetivamente comunitárias e, por isso, escolas públicas não-estatais, e que, portanto, devem ser geridas de forma transparente, 
democrática e participativa; que não podem ter fins lucrativos; que devem ter sua administração subordinada às mantenedoras, para que o controle da administração e da gestão financeira de todos os seus recursos sejam feitas pela comunidade mantenedora e escolar; que isso significa a elaboração e a publicação das demonstrações financeiras certificadas por auditoria independente; que devem submeter-se à auditoria pelo Poder Público a qualquer tempo para que possam ser credenciadas e recredenciadas como instituições comunitárias. Que, por isso, devem adotar uma gestão pedagógica democrática e participativa a partir das diretrizes de uma política educacional da IECLB, sustentada em princípios educacionais, princípios de ética e cidadania gestados na história da cultura protestante com Martin Lutero e John Amos Comenius como expoentes da Reforma Luterana e da construção de um projeto pedagógico humanista, respectivamente, em consonância com os valores desenvolvidos pelo comunitarismo cristão, e, hoje aprofundados e refletidos nos grandes pensadores humanistas de nosso tempo como Paulo Freire e Jürgen Habermas.

Outrossim, nossa tese também assevera que a IECLB e suas escolas comunitárias (Rede Sinodal de Educação), por não desenvolverem um projeto político educacional claro e fundamentado nos valores acima refletidos, estudados e interpretados segundo critérios de uma democracia participativa, se afastaram mutuamente e, assim, permitiram que a escola comunitária evangélica luterana sofresse um processo de elitização, uma espécie de privatização, pela ação das classes sociais mais abastadas e politicamente conservadoras, intensificada no início da década de 90 com o movimento neoliberal; que isso levou estas escolas para uma crise de identidade, uma crise de gestão e uma crise ético-cidadã, negando, assim, ao processo educativo nelas desenvolvido um aprendizado efetivo da ética e da cidadania por todos os seus concernidos: comunidade escolar, comunidade mantenedora e entorno social dessas escolas.

\section{Considerações finais}

Ao concluirmos, defendemos a necessidade da democratização da escola comunitária, pública não-estatal, para que ela possa ressignificar sua concepção de educação herdada da história das escolas comunitárias de confissão luterana, ou seja, a concepção de uma educação enquanto um que fazer para tornar o ser humano mais ser humano através de uma educação emancipadora e libertadora. Isto significa que a concepção de educação comunitária de confissão luterana e seus princípios de ética e cidadania construídos historicamente podem ser um referencial para as escolas da Rede Sinodal de Educação. 
Entretanto, isso passa pela adoção de princípios e processos democráticos participativos como a gestão transparente e democrática das instituições; por uma ressignificação do ensino aprendizagem em sala de aula segundo os critérios da ética e da cidadania participativa; pela construção coletiva de seu projeto político pedagógico; e pela superação dos modelos neoliberais de avaliação . Estes elementos são fundantes para a construção de uma cidadania participativa.

\section{Referências bibliográficas}

AHLERT, Alvori. Educação, ética e cidadania: referenciais para as escolas da Rede Sinodal de Educação. São Leopoldo : Escola Superior de Teologia, 2004. Disponível em: http://www.est.edu.br/biblioteca/btd/ahlert_d.htm

IECLB. DEPARTAMENTO de Educação. Regulamento.(Mimeografado).

IECLB. Relatório do Pastor Presidente ao XIV Concílio Geral Ordinário da IECLB. Marechal Cândido Rondon, PR, outubro de 1984.

IECLB. Relatório do Pastor Presidente ao XV Concílio Geral Ordinário da IECLB. Rio de Janeiro, RJ, outubro de 1986.

IECLB. Departamento de Educação. Educação e Constituinte. São Leopoldo, 1986.

IECLB. Informações IECLB. Ano X, N. 94, Porto Alegre, RS, Outubro de 1988.

IECLB. Relatório do Pastor Presidente ao XVII Concílio Geral Ordinário da IECLB. Três de Maio, RS, outubro de 1990.

IECLB. Diretrizes de uma política educacional da IECLB. Boletim Informativo do Conselho Diretor. Porto Alegre, N. 117, 24 de agosto de 1990.

IECLB. Relatório do Pastor Presidente ao XVIII Concílio Geral Ordinário da IECLB. Pelotas, RS, outubro de 1992.

IECLB. Conselho de Educação. Escola \& Qualidade. São Leopoldo : Departamento de Educação - IECLB, 1994. (Série Documentos 1).

IECLB. Conselho de Educação. Conselho Escolar: atribuições e compromissos na administração geral da escola evangélica. São Leopoldo: Departamento de Educação, 1994. (Série documentos 2).

IECLB. Conselho de Educação. Professor: um perfil - um estudo sobre a autopercepção do professor da escola confessional evangélico-luterana. São Leopoldo: Departamento de Educação, 1996. (Série Documentos 3). 
IECLB. Relatório do Pastor Presidente ao XX Concílio Geral Ordinário da IECLB. Toledo, PR, outubro de 1996.

IECLB. Relatório do Pastor Presidente ao XXI Concílio Geral Ordinário da IECLB. Rodeio, SC, outubro de 1998.

IECLB. Departamento de Educação. Livro de Atas da Associação Evangélica de Educação (AEE): 1981-1990.

IECLB. Departamento de Educação. Livro de Atas do Conselho de Educação (1981-1985).

IECLB. Departamento de Educação. Livro de Atas do Conselho de Educação (1985-1990).

IECLB. Conselho de Educação. Ata N. 61, 16 e 17 de abril de 1999. (Sistema informatizado).

IECLB. Conselho de Educação. Ata N. 63, 17 e 18 de setembro de 1999. (Sistema informatizado).

IECLB. Conselho de Educação. Ata N. 66, 1 e 2 de setembro de 1995. (Sistema informatizado).

IECLB. Conselho de Educação. Ata N. 71, 23 e 24 de novembro de 2000.(Sistema informatizado).

IECLB. Conselho de Educação. Ata N. 72, 26 e 27 de abril de 2002. (Sistema informatizado).

IECLB. Conselho de Educação. Ata N. 75, 22 e 23 de novembro de 2002. (Sistema informatizado).

IECLB. Pré-Consulta: Por uma política educacional da IECLB - Educação Formal (Conclusões). Secretaria Geral. IECLB, N. 24555/00. (Mimeografado).

IECLB. Relatório da Direção da Igreja - XXIII Concílio Geral da Igreja. Santa Maria do Jetibá, ES, 16 a 20 de outubro de 2002.

IECLB. Pré-Consulta: Por uma política educacional da IECLB - Educação Formal (Conclusões). Secretaria Geral. IECLB, N. 24555/00. (Mimeografado).

IECLB. Relatório da Direção da Igreja. XXIII Concílio da Igreja. Santa Maria do Jetibá, ES, 16 a 20/10/2002.

KREUTZ, Lúcio. Escolas comunitárias de imigrantes no Brasil: instâncias de coordenação e estruturas de apoio. Revista Brasileira de Educação. ANPED, n. 15, 2000, p. 159-176. 
LAUBE, Adolf. Martin Luther in der Erbe - und Traditionsauffassung der DDR. In: LÖWE, Hartmut; ROEPKE, Claus-Jürgen. (Hg.) Luther und die Folgen. München: Kaiser, 1983. p. 135-159.

LIBÂNEO, João Batista. Ideologia e cidadania. São Paulo: Moderna, 1995.

LINDBERG, Carter. Reformas na Europa. São Leopoldo: Sinodal, 2001.

LUTERO, Martinho. Os catecismos. Porto Alegre/São Leopoldo: Concórdia/Sinodal, 1983.

LUTERO, Martinho. Pelo Evangelho de Cristo. Porto Alegre/São Leopoldo: Concórdia/Sinodal, 1984.

LUTERO, Martim. Ética cristã. São Leopoldo: Sinodal, 1999. (Coleção Lutero para hoje).

LUTERO, Martim. Educação e reforma. São Leopoldo: Sinodal, 2000. (Coleção Lutero para hoje).

LUTERO, Martin. Política, fé e resistência. São Leopoldo: Sinodal, 2000. (Coleção Lutero para hoje).

LUTERO, Martin. Economia e ética : comércio e usura - $1^{a}$ parte. São Leopoldo: Sinodal, 2001. (Coleção Lutero para hoje).

PAULY, Evaldo Luis. Ética, educação e cidadania: questões de fundamentação teológica e filosófica da ética da educação. São Leopoldo : SINODAL, 2002.

STRECK, Danilo R. \& WACHS, Manfredo C. Educação cristã. In: SCHNEIDERHARPRECHT, Cristoph (org.). Teologia Prática no contexto da América Latina. São Leopoldo : Sinodal : ASTE, 1998, p. 245-267).

STRECK, Danilo Romeu. Perspectiva luterana da educação (IECLB). In: STRECK, Danilo Romeu (org.). Educação e Igrejas no Brasil: um ensaio ecumênico. São Leopoldo : Ciências da Religião/CELADEC/IEPG, 1995. 